\title{
Editorial
}

\section{History of Phonocardiographic Stuöies in Japan}

\author{
Kunio Yamakawa, M.D.*
}

WEN describing the brief history of the studies on PCG in Japan, the
name of Late Professor Toshikazu Mashimo, formerly the Professor of Internal Medicine of Kyoto University comes to my mind. Unfortunately, he died in the severe typhoon at Hiroshima while inspecting the atomic bomb casuality in October of 1945 . He was the founder of Japanese Circulation Society and the teacher of Prof. M. Maekawa, the present editor of Japanese Circulation Journal. In 1927 he had already demonstrated the phonocardiograms taken with an electromagnetic microphone, transformer coupled amplifier and electromagnetic oscillograph. Later for the period of 10 years many far advanced studies in circulatory research by means of newly developed electronical technics, especially in the field of PCG had been made at Profcssor Mashimo's clinic in Kyoto University.

These reports were summarized in the Monograph entitled "Functional Studies of Circulatory Disease" (1947), but unfortunately it was written in Japanese and therefore was not known worldwide.

I personally think that Dr. Koizumi's method of a condenser microphone which uses the body as one pole, was a progress unique to Japan. Dr. Koizumi reported their original work in Klinische Wochenschrift 19 Jahrgang (11091112) 1940.

The recent study of Groom and Sihvonen was very similar in principle to that of Dr. Koizumi's. Dr. Hinohara attached a small metal road at the tip of a long rubber stomach tube in which was a lead wire. With this method he was able to record a very clear esophageal PCG. Drs. Tomomatsu and Takasaki applied this technic to an intracardiac catheter in 1946 and made a short report postulating that this technic could be utilized to get more precise information of the venous return to the right atrium. At this time, independent of Dr. Tomomatsu's work and together with my colleagues Drs. Kitamura, Shionoya, Yamamoto, Nagai and Ohta, I had planned to pick up the prototype of heart sounds from each heart cavity, which were not interfered by skin, fatty tissue, ribs, lung and so on.

* Professor of Internal Medicine, Juntendo University, School of Medicine, Tokyo. 
A shielded wire was threaded into a vinyl tube, about the size of Cournand $\mathrm{F} 7$ or 8 , and was completely sealed with bakelite varnish. This became a handmade intracardiac phonocatheter. Unfortunately my apparetus is difficult to handle and one has to search patiently for the keenest tuning point, and sometimes takes hours for the untrained.

But once it is set my apparatus has a very good frequency characteristics, especially in lower frequency range, and is especially suited for study of the low frequency components such as the atrial sound, and these results were reported in 4th World Congress of Cardiology of Mexico-city and was published in Memorias del 4 Congreso Mundial de Cardiologia Tome I-B, 336344, 1963.

Almost about the same time, Dr. Soulié et al. in France had reported another method. Some years later, Drs. David Lewis, Moscovitz and A. Luisada had reported various excellent methods of intracardiac phonocardiograms.

At present many clinical phonocardiographical investigations are now carried on in Japan and is especially actively pursued in Prof. H. Ueda's clinic in Tokyo University.

In the 3rd Asian Pacific Congress of Cardiology, the Symposium on Phonocardiography was held in Kyoto last year, under the chairmenship of Drs. A. Luisada, K. Holldack and myself.

Dr. M. Nellen from Cape-Town, Dr. H. Bose from Calcutta and many Japanese doctors participated in this meeting.

The symposium was successful in one respect that these leading foreign doctors provided much inspiration to all the younger participants.

Several years ago Dr. T. Sakamoto of Tokyo University, and Dr. S. Yoshimura of Jikei University published independently excellent monographs on phonocardiography. Another introductory book on phonocardiography was recently published by collaboration of active investigators, such as Drs. Yoshimura, Ohta, Kitamura and Watanabe. Many young cardiologists in Japan are now showing keen interest to phonocardiography and it is expected that further original research will be forthcoming in the near future of Japan. 